\title{
Using the Scanning Electron Microscope for a Summer Forensics Camp
}

\author{
R. Weinkauf, * J. Watkins, **
}

* Occupational Programs and Economic Development, Schoolcraft College, 18600 Haggerty Road, Livonia, MI 48152-2696

** Sciences Division, Schoolcraft College, 18600 Haggerty Road, Livonia, MI 48152-2696

Access to a scanning electron microscope (SEM) isn't often extended to undergraduate science students, much less to high school students. Through a local partnership Schoolcraft College was able to provide the opportunity for high school and community college students to use a scanning electron microscope as a tool to solve a fictional crime.

Schoolcraft College is a community college located in Livonia, Michigan. The total student enrollment tops 39,000. Schoolcraft serves the southeastern lower Michigan counties of Wayne, Oakland, Washtenaw and primarily the surrounding Detroit suburbs. It serves as a feeder school for University of Michigan-Dearborn, Wayne State University, Eastern Michigan University, Madonna University and Lawrence Technological University.

The partnership that provides this opportunity evolved from a desire to interest high school students in science, technology, engineering and mathematics (STEM) careers, and to also encourage enrollment of this population in our institution. Discussions began with nearby Lawrence Technological University located in Southfield, Michigan to explore strategies to introduce high school students to faculty and facilities at both Schoolcraft College and Lawrence Tech, and thereby create interest in the attendees of the science camp to matriculate. Lawrence Tech is a four-year university offering undergraduate and graduate programs in science, computer technology and engineering.

Previous experience with attempts to interest high school students in science-focused summer programs met with declining enrollment. Schoolcraft College's "Kids On Campus" program has been very successful with enrolling children between 5 and 12 years old in science educational programs, however participation in science camps past the age of 12 was less than satisfactory. An informal discussion with leadership of Lawrence Tech's Natural Sciences division revealed that they had enjoyed renewed interest in a summer science program by packaging it around the theme of forensics and crime scene investigation. The popularity of many CSI and forensic-themed dramas on television fed the interest to the point where capacity became a problem for LTU's summer program. A partnership was formed to pool the faculty and equipment resources of both institutions for the Summer 2008 program.

While planning for the 2008 Forensic Summer Science Institute (FSSI) was ongoing, Schoolcraft was involved in the purchase and installation of a Zeiss EVO LS-15 SEM. Installation was completed in September 2008, ready in time for fall classes but too late to be incorporated into the Summer 2008 FSSI. Commitment to use the Schoolcraft Imaging and Analysis Lab for the 2009 FSSI program was made and planning began again in October 2008. 
The FSSI runs two weeks of the summer, each with a different crime scenario. Students sign up for one of the two sessions based on availability. Admission to the FSSI is competitive and acceptance in the program is based on a review of their academic record.

Planned around a set of science competencies determined in advance by the faculty, lecture and lab instruction are delivered for each module. Lecture and lab relate the biology, chemistry, physics and mathematics competencies to the forensic science context.

The SEM is brought into play to introduce forensic botany and palynology, forensic geology, hair and fiber analysis or material transfer. A Gun Shot Residue analysis option is also installed on the SEM and will be incorporated in future FSSI programs.

Students are assembled into teams for the FSSI week and perform the science and evidence gathering as a team. Emphasis is on following good procedure and exercising critical thinking to relate the results of the science modules to include or exclude possible suspects. The week culminates in team presentations where each group of students summarizes their conclusions of the crime scene timeline and which suspect is ultimately involved in the crime.

The use of a scanning electron microscope for this program has increased enthusiasm among participants, steered some students to consider a career in sciences and enriched their continuing journey as students of science.

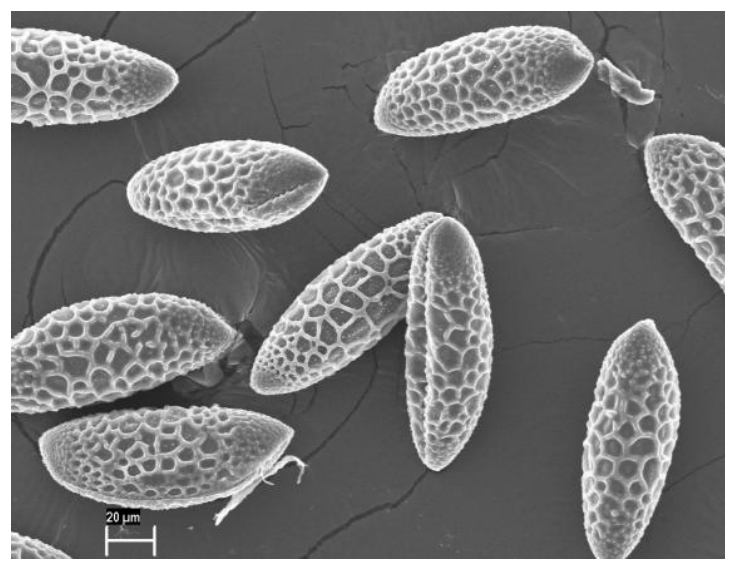

Fig. 1. Lily pollen evidence from suspect

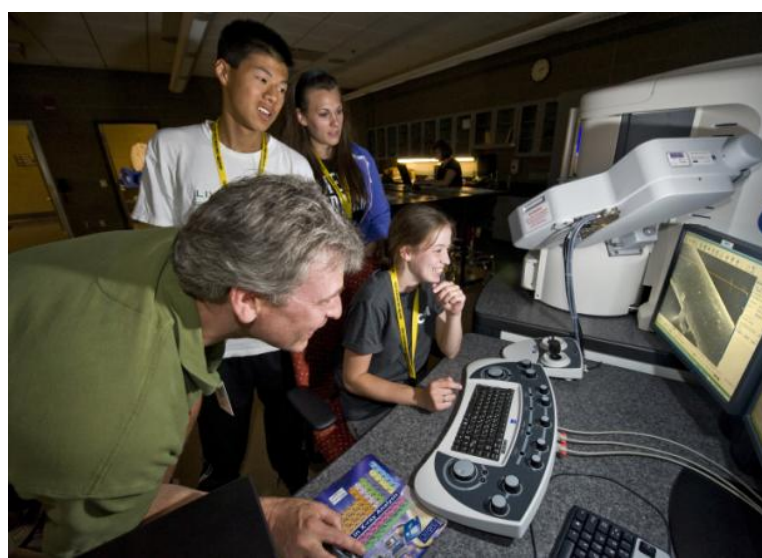

Fig. 2. FSSI students operating SEM. 